\title{
A JUSTICA E AS NORMAS DE SOBREDIREITO: O LUGAR DAS REGRAS DE CONEXÃO EM DIREITO INTERNACIONAL PRIVADO
}

\author{
Leandro de O. Moll ${ }^{*}$
}

1. Introdução - 2. As Regras de Conexão em DIP - 3. A Justiça como Fundamento das Regras de Conexão - 4. A "Revolução" do Método Conflitual e a Justiça como Fim das Regras de Conexão - 5. A Teleologia como Método de um DIP comprometido com a Justiça - 6. Perspectivas para o DIP Brasileiro - 7. Conclusões - 8. Referências.

Palavras-chave: Direito Internacional Privado; Justiça; Regras de Conexão; Lei de Introdução ao Código Civil Brasileiro;

Resumo: O Direito Internacional Privado se ocupa dos problemas decorrentes de situações jurídicas privadas de dimensão internacional. Sua principal função é orientar o juiz competente no momento de decidir qual a lei aplicável a uma controvérsia que tenha contato com mais de um ordenamento jurídico, razão pela qual é classificado como espécie de "sobredireito". Seu principal objetivo é indicar ao juiz nacional, mediante a utilização de "regras de conexão", a lei mais adequada para reger uma relação jurídica privada de dimensão internacional (determinar o "centro de gravidade da relação jurídica"), mesmo que aquela lei seja uma lei estrangeira. Conhecido como o "direito da tolerância" não pode prescindir de considerações de justiça, seja no seu fundamento e sua obrigatoriedade, seja na sua aplicação. Com efeito, como toda norma jurídica, as regras de conexão também devem estar comprometidas com o valor final da justiça, razão pela qual é preciso rever a utilização de regras de conexão rígidas, inflexíveis e mecânicas, inclusive por fidelidade ao objetivo primeiro do Direito Internacional Privado, esclarecido pelos Pais da disciplina, a saber, o da determinação da lei mais adequada e justa para o problema dos conflitos de leis. Nesse contexto, importa proceder a uma modernização do Direito Internacional Privado brasileiro - tendo em vista as várias tendências internacionais em doutrina, jurisprudência e legislação - com o intuito de torná-lo menos mecânico e mais comprometido com a justiça substantiva.

\section{Introdução}

Uma regra que não tem por preocupação a justiça é digna de ser chamada "norma jurídica"? Durante séculos, filósofos e jus-filósofos das mais diversas matizes têm

\footnotetext{
* Mestre em Direito Internacional pela Universidade do Estado do Rio de Janeiro. Professor de Direito Internacional Privado no Centro Universitário de Brasília (UniCEUB). Diplomara de carreira.
} 
tentado encontrar os contornos da justiça, e o modo com que este valor - tão aspirado e de difícil apreensão - se relaciona com o direito.

A discussão acerca do papel da justiça na ciência jurídica é geralmente feita tendo-se por base o direito substantivo, que determina o "dever-ser" no âmbito de sua função solucionadora de controvérsias materiais, atribuindo direitos e obrigações aos sujeitos de direito. $\mathrm{O}$ sobredireito, i.e., o conjunto de normas que indica o direito substantivo aplicável à solução material dos litígios - seja na dimensão temporal (direito intertemporal), seja na espacial (Direito Internacional Privado) - é por vezes negligenciado no que toca ao centro da preocupação dos estudiosos da justiça, talvez pela falsa percepção de que o sobredireito não seria, de fato, direito.

O Direito Internacional Privado (DIP) surgiu com a finalidade de resolver conflitos de leis no espaço, quando uma determinada situação jurídica vincula-se a mais de um sistema normativo, como no caso de um casamento entre pessoas de nacionalidades diferentes, de um contrato realizado entre partes domiciliadas em países distintos, ou de um acidente de automóvel envolvendo pessoas domiciliadas em países diferentes, ocorrido num terceiro país. Em situações como essas, o DIP deve indicar ao juiz competente a lei que deverá ser aplicada, podendo inclusive determinar que o juiz local aplique, no exercício de sua jurisdição, lei estrangeira - razão pela qual é conhecido como "direito da tolerância". Mas se o objetivo do DIP é tão simplesmente indicar o direito material aplicável a um caso pluriconectado, qual seria, de fato, o papel da justiça no âmbito desta disciplina?

Não procuraremos tratar, neste estudo, de temas tão caros à Teoria da Justiça como o conteúdo do justo ou de reflexões sobre a justiça em suas diversas acepções. Antes, buscaremos demonstrar que o DIP, na condição mesma de sobredireito, tampouco pode prescindir de uma reflexão finalística ou teleológica no que respeita às consequiências práticas de sua aplicação em casos concretos. A preocupação com o resultado material (justeza das decisões) em decorrência da aplicação de normas jurídicas é, aliás - ao menos para parte significativa dos teóricos (particularmente os de cunho não positivista) - elemento imprescindível para a aceitação de um norma 
como "jurídica". Procuraremos demonstrar que o DIP não escapa, ou não deve escapar, a esse pressuposto.

Para tanto, após tecermos breves considerações acerca da estrutura clássica, ortodoxa das regras de conexão em DIP, passaremos a analisar o fundamento dessas mesmas regras e a forma em que evoluiu historicamente.

Em seguida, trataremos das modificações que vêm sofrendo as regras de conexão a partir da necessidade do desenvolvimento de métodos que melhor possibilitem o DIP a atingir a sua finalidade, a saber, determinar a lei mais adequada para reger uma situação jurídica privada de dimensão internacional (situação jurídica pluriconectada).

A seguir, consideraremos críticas a métodos conflituais e tentativas de tornar o DIP mais eficaz na consecução de sua finalidade.

Finalmente, antes de concluirmos, analisaremos a situação dos conflitos interespaciais no âmbito do direito brasileiro, suas dificuldades e possíveis caminhos para superálas.

\section{As Regras de Conexão em DIP}

Sói identificarem-se, na doutrina de DIP, quatro grandes temas de se ocupa esta disciplina, a saber, o conflito de jurisdições, o conflito de leis, nacionalidade e condição jurídica do estrangeiro. ${ }^{1}$ Essa concepção, ampla, tem origem na doutrina francesa e teve grande influência sobre os juristas brasileiros, ${ }^{2}$ muito embora alguns autores prefiram a abordagem mais restrita, adotada pelos anglo-saxões, os quais restringem o objeto do DIP a três aspectos básicos: o conflito das leis, o conflitos das jurisdições e o reconhecimento de sentenças estrangeiras. ${ }^{3}$

\footnotetext{
oficial do Ministério das Relações Exteriores do Brasil

${ }^{1}$ DOLINGER, Jacob. Direito internacional privado: parte geral. 5. ed. Rio de Janeiro: Renovar, 1997, p. 1.

${ }^{2}$ VALLADÃO, Haroldo. Direito internacional privado. 4. ed. Rio de Janeiro: Freitas Bastos, 1974, p. 44-45; DOLINGER, Jacob, op. cit., p. 2.

${ }^{3}$ DOLINGER, Jacob, op. cit., p. 2; ARAÚJO, Nadia de. Direito internacional privado: teoria e prática brasileira. Rio de Janeiro: Renovar, 2003, p. 30.
} 
Malgrado as divergências acerca do objeto do DIP, os autores convergem ao menos quanto à aceitação daquele que é o tema mais marcante deste ramo do direito: o conflito de leis. Entre os alemães e anglo-saxões, substitui-se a própria denominação “internationales Privatrecht" ou "private international law" por "Kollisionsrecht" e "Conflict of Laws".

Esse tópico característico do DIP tem por objetivo determinar a lei material aplicável a uma situação jurídica conectada com mais de uma legislação. A esse respeito, acentua Jacob Dolinger que:

\begin{abstract}
"o Direito Internacional Privado, ao trabalhar com o conflito das leis, inegavelmente o campo mais amplo e importante de seu objeto, há de criar regras para orientar o Juiz sobre a escolha da lei a ser aplicada. $\mathrm{O}$ conflito entre as legislações permanece, mas a situação concreta é resolvida mediante a aplicação de uma das leis, escolhida de acordo com as regras fixadas, seja pelo legislador, seja pela Doutrina ou pela Jurisprudência". 4
\end{abstract}

O conflito de leis dá origem, pois, ao principal método do DIP, que visa a capacitar o julgador a escolher, dentre as várias legislações conectadas com a situação, o sistema jurídico a ser aplicado para regê-la. As normas de conexão ou regras de conexão constituem, assim, o instrumental de que se utiliza o juiz no processo de escolha da lei aplicável à relação jurídica privada de dimensão internacional. Têm elas a função de indicar o direito que vai solucionar - este sim de modo substantivo - a controvérsia de fundo.

É nesse sentido que se diz que o DIP tem a natureza de sobredireito ou de "direito sobre direito", já que não resolve ele mesmo o litígio, mas indica a lei substantiva que irá resolvê-lo, quando duas ou mais delas seriam, em tese, passíveis de aplicação. ${ }^{5}$

As regras de conexão incidem em diferentes áreas do direito, tais como direitos reais, direito de família, contratual, atos ilícitos, direito de sucessões etc. Para cada um

\footnotetext{
${ }^{4}$ DOLINGER, Jacob, op. cit., p. 5.
} 
desses campos, o DIP determina a aplicação de regras de conexão específicas com o intuito de resolver os conflitos pluriconectados. Está-se aí diante da chamada "parte especial" do DIP, constituída de regras de conexão que a doutrina alemã denomina de “normas de colisão independentes"(selbständige Kollisionsnormen). ${ }^{6}$

Já a "parte geral" do DIP engloba as "normas de colisão dependentes" (unselbständige Kollisionsnormen), que constituem normas auxiliares (Hilfsnormen), já que têm por função socorrer o juiz na determinação da lei aplicável quando as normas independentes (regras de conexão) não forem suficientes para fazê-lo por si sós. ${ }^{7}$ São exemplos de normas incluídas na "parte geral" do DIP os princípios da ordem pública, da fraude à lei, do reenvio e dos direitos adquiridos. O seu papel primordial é o de possibilitar que o juiz afaste a aplicação da lei material estrangeira indicada pela regra de conexão do foro quando aquela for incompatível com a ordem pública local; quando se constatar que as regras de conexão foram manipuladas por fraude à lei; quando o DIP estrangeiro do ordenamento indicado remeter a aplicação da lei de um terceiro país para a solução da controvérsia; ou quando a aplicação da lei indicada contrariar direitos previamente adquiridos pelo indivíduo.

Posto isso, e na medida em que o DIP constitui espécie de sobredireito que visa, através das regras de conexão, resolver os conflitos de leis no espaço - e não as controvérsias substantivas surgidas no seio da sociedade - pergunta-se de que modo o valor da justiça atua ou teria lugar nesta disciplina. É o que se procurará responder nos itens que se seguem.

\section{A Justiça como Fundamento das Regras de Conexão}

A idéia de regras de conexão em DIP consolidou-se a partir das escolas estatutárias, que atuaram entre os séculos XIV e XVIII, dando origem, na Idade Média, ao método conflitual de DIP. ${ }^{8}$

\footnotetext{
${ }^{5}$ ARAUJO, Nadia de, op. cit., p. 31; DOLINGER, Jacob, op. cit., p. 297.

${ }^{6}$ HOFFMANN, Bernd von. Internationales Privatrecht. 7. ed. Munique: Beck, 2000, p. 165.

${ }^{7}$ Idem.

${ }^{8}$ ARAUJO, Nadia de, op. cit., p. 32.
} 
O termo "estatutárias" remete aos "Estatutos" - leis locais adotadas pelas várias cidades do norte da Itália, independentes do direito romano e do direto germânico. ${ }^{9}$ Era preciso que se encontrasse uma solução para a lei aplicável a um litígio envolvendo dois indivíduos, provenientes de cidades diversas, com leis distintas, litigando perante o mesmo juiz. Às várias teorias sobre soluções de conflitos correspondem as diversas escolas estatutárias.

Dentre os juristas da época, destaca-se a figura de Bartolo de Sassoferrato, da escola estatutária italiana, que desenvolveu, entre outros aspectos da teoria de DIP, soluções como a de que "a lei do lugar do contrato é adotada para as obrigações dele emanadas, enquanto que a lei do lugar de sua execução rege as conseqüências da negligência ou da mora na execução". 10

O que importa ressaltar aqui é a ênfase dada, naquela época, à territorialidade das leis, e que, por outro lado, o seu efeito extraterritorial (sua aplicação por um juiz de outra jurisdição) só era possível em decorrência da comitas gentium (cortesia internacional), i.e., dependia de um mero ato de generosidade do foro. ${ }^{11}$

O século XIX viria a testemunhar o advento das doutrinas modernas de DIP, em que se destacaram juristas como Joseph Story, Friedrich Carl von Savigny e Pasquale Mancini.

Juiz da Suprema Corte norte-americana em meados do século XIX, Story deu grande contribuição à disciplina ao substituir o fundamento da cortesia internacional para a aplicação de leis estrangeiras pela "noção de que a aplicação do direito estrangeiro se faz na busca pela boa justiça". ${ }^{2}$

Tal concepção foi reforçada com uma decisão de um tribunal britânico no caso Warrender $v$. Warrender, em que se consignou que "as cortes [...] recorrem à lei do país em que se fez o contrato, não ex comitate, mas ex debito justitiae". ${ }^{13}$

\footnotetext{
${ }^{9}$ DOLINGER, Jacob, op. cit., p. 115.

${ }^{10}$ Ibidem, p. 117.

${ }^{11}$ ARAUJO, Nadia de, op. cit., p. 33.

${ }^{12}$ DOLINGER, Jacob, op. cit., p. 124.

${ }^{13}$ Ibidem, p. 125.
} 
Observa-se, desse modo, uma mudança substancial operada pela nova doutrina, que passou a fundamentar a aplicação de uma lei estrangeira pelo juiz local não em decorrência de cortesia entre as noções, mas em razão de imperativo de justiça. É esclarecedor o pronunciamento de Story quando, defendendo este entendimento, assevera:

"Se em um caso perante corte americana, os direitos das partes dependem de uma transação que teve lugar na França e a transação é de um caráter sobre o qual a lei francesa e a lei norte-americana são diferentes, apresenta-se a questão se a transação se rege pela lei francesa ou não. Se a corte decide que ela se rege pela lei francesa, estará obrigada a aplicar esta lei ao fixar os direitos das partes, não por cortesia, mas porque a justiça assim exige. Os direitos das partes dependem, em parte, das circunstâncias da transação, e em parte, da lei que deu à transação sua força e seu efeitos. Seria tão injusto aplicar uma lei diferente como seria determinar os direitos das partes de acordo com uma transação diferente da que foi realizada". 14

Partindo desse princípio, Story passou a formular regras fixas sobre a lei a ser aplicada diante das diversas situações jurídicas privadas de dimensão internacional levadas a um juiz nacional. Assim é que, por exemplo, determinou que, para reger o estado e a capacidade das pessoas, aplica-se a regra geral do lugar de seu domicílio, para reger os contratos, a lei do lugar de sua feitura e, no caso de direitos reais sobre imóveis, a do lugar onde se situam. ${ }^{15}$

Verifica-se que a doutrina de DIP sofreu fundamental alteração no século XIX, quando se estabeleceu que a aplicação de leis estrangeiras pelo juiz nacional, nos casos em que seja justificada, não decorre de mera cortesia do foro, mas constitui um imperativo de justiça. Sem a aplicação da lei estrangeira, o juiz não estaria aplicando

\footnotetext{
${ }^{14}$ Ibidem, p. 126.

${ }^{15}$ Idem.
} 
o direito legitimamente, uma vez que o jurisdicionado não teria a solução de sua controvérsia através da aplicação do direito adequado.

Desta questão do "direito adequado" voltaremos a tratar no tópico seguinte. Vale registrar aqui, no entanto, que o próprio surgimento do DIP baseou-se na idéia de que, para as situações jurídicas conectadas com mais de uma legislação, seria preciso optar-se pela aplicação daquela que é mais conforme a cada situação ou, nas palavras de Savigny, seria necessário encontrar a "sede da relação em causa". ${ }^{16}$

É este ponto fundamental que se revela, aliás, no texto considerado pela doutrina como a mais antiga manifestação da defesa do método conflitual do DIP. Trata-se da regra elaborada pelo jurista bolonhês Aldricus, da segunda metade do século XII, verbis:

"Mas pergunta-se: se homens de diversas províncias, as quais têm diversos costumes, litigam perante um mesmo juiz, qual desses costumes deve seguir o juiz que recebeu o feito para ser julgado? Respondo: deve seguir o costume que lhe parecer mais preferível e mais útil, porque deve julgar conforme aquilo que a ele, juiz, for visto como melhor. De acordo com Aldricus". ${ }^{17}$

\section{A "Revolução" do Método Conflitual e a Justiça como Fim das Regras de Conexão}

A necessidade de recurso ao método conflitual para resolver as questões privadas de vocação internacional por meio das regras de conexão tornou-se, com a evolução do DIP, por si só, um imperativo de justiça.

Resta saber agora de que forma a aplicação das regras de conexão se vincula também às determinações de justiça.

\footnotetext{
${ }^{16}$ Segundo o professor de Berlim, esta sede seria representada pelo domicílio das pessoas, quando se trata de determinar o seu estado e a sua capacidade; pela localização do bem, para qualificá-lo e regêlo; e o lugar onde se constituíram as obrigações, para solucionar as questões delas decorrentes. Ibidem, p. 128 .

${ }^{17}$ Ibidem, p. 114.
} 
Já foi dito que cabe às regras de conexão indicar, diante do caso concreto, o ordenamento jurídico que deverá reger a situação. Este ordenamento indicado - e não a regra de conexão - será responsável pela solução material ou substantiva para o caso.

Para a concepção clássica das regras de conexão, um problema de DIP "não é um problema de justiça material", mas concerne tão somente "a escolha da lei aplicável indicada pela norma de conflito". ${ }^{18}$ Como ressalta Nadia de Araujo, o objetivo clássico das regras de conexão restringe-se a "promover e garantir a continuidade e a estabilidade das situações jurídicas multinacionais, através da uniformidade da respectiva valoração por parte de diversos sistemas interessados" ${ }^{19}$

Assim sendo, o DIP tradicional teria em vista promover, primordialmente, os objetivos da "igualdade do tratamento das pessoas", da "harmonia das decisões sobre uma mesma relação jurídica", da "previsibilidade das soluções encontradas", das "relações jurídicas universais". ${ }^{20}$

As regras de conexão foram inicialmente concebidas, pois, com formato rígido e inflexível. Os elementos de conexão são, nesse sistema clássico, determinados previamente pela regra de DIP, e, deparado com o caso concreto, o juiz só tem de aplicar a lei referente ao elemento de conexão apontado. Assim é que, por exemplo, o Artigo $9^{\circ}$ da Lei de Introdução ao Código Civil brasileiro determina que "para qualificar e reger as obrigações, aplicar-se-á a lei o país em que se constituírem”. Vêse que, neste caso, a lei estrangeira, quando indicada, será aplicada de modo mecânico pelo julgador: em se tratando de contrato internacional, a lei que irá regê-lo será sempre a do lugar em que foi celebrado. ${ }^{21}$

A insatisfação com a técnica mecanicista de resolver os conflitos de leis fez surgir teorias que lhe fossem alternativas a partir da segunda metade do século XX. Nos

\footnotetext{
${ }^{18}$ ARAUJO, Nadia de, op. cit., p. 37.

${ }^{19}$ Idem.

${ }^{20}$ Ibidem, p. 38.
} 
Estados Unidos, esse movimento de contestação ficou conhecido como "American conflicts revolution".

Uma dessas teorias criou o que viria a denominar-se "princípio da proximidade", e a consagrar-se, nos Estados Unidos, no 2nd Restatement of Conflict of Laws. De acordo com essa abordagem, o julgador, na presença de uma situação de conflito de leis, deve aplicar a lei que apresenta a "conexão mais significativa" (the most significant connection) ou a "relação mais significativa" (the most significant relationship) com o caso concreto. ${ }^{22}$

Este "princípio da proximidade" - que surgiu primeiramente no âmbito dos atos ilícitos e migrou também para outras áreas, como a dos contratos internacionais - tem por objetivo livrar o juiz do engessamento a que lhe submetem as regras de conexão clássicas, inflexíveis. Com efeito, verificou-se que os tribunais estavam recorrendo cada vez mais a princípios excepcionais de DIP (tais como a ordem pública, reenvio e qualificação) com o intuito de afastar a aplicação da lei indicada pelas regras de conexão rígidas. Nas palavras de Juenger, "using renvoi, characterization and public policy in manipulative fashion courts were able to reach just decisions". 23 A aplicação do princípio da proximidade, por outro lado, aumenta em muito a discricionariedade do juiz para buscar a "sede das relações jurídicas", e não é difícil observar que a sua generalização tende a diminuir a necessidade de recurso a institutos como a ordem pública, a qualificação e o reeenvio, a fraude à lei e direitos adquiridos. ${ }^{24}$

Uma outra alternativa às regras de conexão clássicas teve cunho unilateral. Trata-se da "análise de interesse governamental" (governmental interest analysis) de Brainerd Currie, que determina que a lex fori só não deve ser aplicada se se constata que o Estado do foro não teria interesse em ver a sua lei aplicada à hipótese e se demonstra que o Estado estrangeiro o teria. ${ }^{25} \mathrm{Um}$ dos critérios para verificar-se a presença do

\footnotetext{
${ }^{21}$ O DIP clássico cuidou de desenvolver também normas que afastam a aplicação mecânica da lei estrangeira. Trata-se de princípios como a ordem pública e a fraude à lei que, de certa forma, dão certa margem ao foro para escapar à determinação rígida da sua regra de conexão.

${ }^{22}$ JUENGER, Friedrich K. Choice of law and multistate justice. Dordrecht: Martinus Nijhoff, 1992, p. 96-97.

${ }^{23}$ Ibidem, p. 96.

${ }^{24}$ DOLINGER, Jacob, TIBURCIO, Carmen. O DIP no Brasil no século XXI. Revista Mexicana de Derecho Internacional Privado, número especial, 2000, p. 80.

${ }^{25}$ JUENGER, Friedrich K., op. cit., p. 98-99.
} 
interesse do Estado seria, por exemplo, a aplicação da lei nacional a seus nacionais e residentes.

Pode-se observar, por outro lado, que tanto a teoria que consagra o princípio da proximidade (the proper law approach), tanto a interest analysis de Currie, além das teorias ecléticas e mistas - que aproveitam elementos presentes em ambas - não apresentam nada novo em substância, na medida em que constituem teorias ainda muito preocupadas com o elemento territorial. ${ }^{26}$

De fato, a abordagem da lei mais próxima - de viés multilateral - não deixa de ser um desdobramento da teoria sistematizada por Savigny, segundo a qual o método conflitual tem por objetivo determinar a aplicação da "sede das relações jurídicas", o seu centro de gravidade. Se isto é feito através de regras de conexão rígidas ou flexíveis é, em grande escala, uma opção do legislador sobre como tal objetivo será melhor atingido.

O unilateralismo da concepção de Currie, por sua vez, remete às escolas estatutárias anteriores ao século XIX, extremamente provincianas e ciosas da aplicação da lex fori sempre que não se prove a existência de elementos contrários que justifiquem a consideração de legislação alienígena.

Há que se admitir, entretanto, que a "revolução" na estrutura das regras de conexão evidenciaram a insuficiência de regras mecânicas, rígidas e inflexíveis, chamando a atenção para a necessidade de não se perder de vista o objetivo primordial do DIP - o de "promover a regulamentação adequada e materialmente mais justa da questão plurilocalizada", deixando-se de considerá-lo "um mero direito de remissão" e passando-se a vê-lo como um verdadeiro "direito de decisão", ${ }^{27}$

O advento do princípio da proximidade, por exemplo, dá maior poder ao magistrado para a escolha da lei com a qual o caso apresenta "vínculos mais estreitos", o que permite que seja afastada, de imediato, a aplicação de uma lei que não tenha relação mais próxima com a situação pluriconectada, dando maior discricionariedade ao

\footnotetext{
${ }^{26}$ Ibidem, p. 151-154.
} 
julgador na busca pela lei mais adequada. ${ }^{28}$ Por outro lado, o pluralismo de métodos a que se submete o DIP contemporâneo permite a maior utilização de recursos de cunho unilateral como o preconizado pelas "leis de aplicação imediata", que nada mais são que normas domésticas do foro que devem ser invariavelmente aplicadas pelo juiz local independentemente do que disponha a regra de conexão correspondente ao caso, tendo em vista o valor que o ordenamento do foro dá a que certos litígios sejam resolvidos de determinada maneira.

Aplicados de modo adequado pelo Judiciário local, portanto, o novo pluralismo de métodos do DIP permite a que se chegue a resultados mais satisfatórios e justos, de acordo com o caso concreto e os valores substantivos envolvidos. Em outras palavras, o resultado do conflito de leis, formal, passa a ser mais comprometido com valores de fundo, relacionando-se com o resultado material obtido pela aplicação lei indicada.

Vê-se, com isso, que o DIP tem procurado responder à necessidade de que não fique restrito a um sobredireito mecânico e descomprometido com o resultado material de casos pluriconectados. A finalidade de justiça em DIP, aliás, vinha e vem sendo preconizada pelos tribunais de países que ainda adotam puramente as regras de conexão clássicas, através do recurso a princípios da chamada "parte geral" da disciplina, com o intuito de fugir à aplicação do direito material indicado pela regra de conexão rígida que não seria, contudo, adequado para a solução do caso concreto.

\section{A Teleologia como Método de um DIP comprometido com a Justiça}

Dentre os que se negam a aceitar a "revolução" do conflito de leis como o ponto final de um processo de aprimoramento dos métodos de DIP destaca-se o professor Friedrich Juenger, da Universidade da Califórnia. Este autor tem uma visão bastante crítica acerca da eficácia dos métodos conflituais que se propagam, especialmente no que tange à sua incapacidade de considerar adequadamente a justiça material como resultado a ser atingido.

\footnotetext{
${ }^{27}$ ARAUJO, Nadia de, op. cit., p. 47.

${ }^{28}$ O método multilateral dos "vínculos mais estreitos" tem sido adotado por muitas legislações nacionais e convenções internacionais de DIP. Para um panorama de sua positivação, ver JUENGER, Friedrich K., op. cit., p. 179-185 e ARAUJO, Nadia de, op. cit., p. 49-64.
} 
Para Juenger, tanto os unilateralistas quanto os multilateralistas perdem-se na tentativa de encontrar uma "localização geográfica" portadora do direito a ser aplicado. Partiriam eles de uma concepção (equivocada) de que é possível e necessário localizar o direito material e as relações jurídicas através de elementos de conexão. ${ }^{29}$

É verdade que, ao que parece, os valores buscados por essas regras continuam a ser, predominantemente, os de uniformidade, previsibilidade e consistência das decisões. Entretanto, esses objetivos não podem ser garantidos, já que cada tribunal pode optar pela prevalência de elementos de conexão divergentes e essa escolha acaba sendo, em última instância, arbitrária. Os conflitos de segundo grau (isto é, aqueles causados em decorrência da adoção de regras de conexão diversas entre os diferentes Estados) permanecem, e, assim também, a insegurança e a falta de uniformidade das decisões.

No que diz respeito ao método multilateral, não se pode garantir que o juiz, ao determinar a lei que tem a relação mais significativa com o caso, estará escolhendo a mais justa, a que promova os valores substantivos apropriados. O mesmo se diga no que tange ao método unilateral dos interesses governamentais. Há aí o risco de manipulação das regras conflituais pelo julgador. Nas palavras de Juenger,

"while the proper law approach and interest analysis confer
praetorian powers upon courts, they fail to provide guidance on
how to exercise these powers. Accordingly, doctrines that operate
by stealth undermine predictability without necessarily producing
sound decisions".

A interessante comparação entre dois casos julgados pela Corte de Apelação de Nova Iorque pode ser feita para demonstrar as deficiências inerentes às "novas" regras de conexão.

O primeiro é o famoso caso Babcock v. Jackson, decorrente de ação indenizatória por acidente automobilístico ocorrido no Canadá. A corte, adotando o princípio da

${ }^{29}$ JUENGER, Friedrich K., op. cit., p. 154. 
proximidade, afastou a clássica regra de conexão segundo a qual a lei aplicável a atos ilícitos internacionais é a do lugar da ocorrência do ilícito (lex loci delicti), determinando a aplicação da lei nova iorquina, eis que tanto o condutor do automóvel quanto a vítima eram domiciliados em Nova Iorque, e que o automóvel era registrado também nesse Estado. Assim sendo, a corte considerou que o fato de o acidente ter tido lugar no Canadá era secundário em face dos demais elementos de conexão que vinculavam a situação preponderantemente ao direito de Nova Iorque, que, por sinal, era mais benéfica ao autor/vítima que a lei canadense. ${ }^{31}$

Anos mais tarde, a corte de Nova Iorque teve de decidir sobre a lei aplicável ao pedido de indenização por abuso sexual de dois menores, ocorrido num campo de escoteiros no Estado de Nova Iorque (Schultz v. Boy Scouts of Am. Inc.). ${ }^{32}$ As vítimas e seus pais eram domiciliados em Nova Jérsei, a associação dos escoteiros era sediada neste Estado quando da ocorrência do ilícito. Aplicando a regra da lei com os vínculos mais estreitos, a corte extinguiu o processo sem julgamento de mérito, em conformidade com a lei de Nova Jérsei, o que não teria ocorrido se tivesse sido aplicada a lei de Nova Iorque - como queriam os autores - neste que pode ser considerado como "o caso Babcock invertido".

Como se vê, a tentativa de se chegar a uma coerência na aplicação das regras de conexão em nome da previsibilidade das decisões pode prejudicar a prolação de uma decisão justa e coerente com determinados valores e princípios substantivos (como o da aplicação mais benéfica à vítima, à criança, ao consumidor etc.) em uma e outra decisão. Nas palavras de Juenger, “once a court has localized a particular transaction in a certain way, the principle of stare decisis comes into play and requires the same localization when the law that has 'the most significant relationship' hurts the victim". 33

Segundo esse autor, portanto, a verdadeira distinção doutrinária, no âmbito da controvérsia que aqui examinamos, não deveria ser entre clássicos e

\footnotetext{
${ }^{30}$ Ibidem, p. 177.

${ }^{31} 12$ N.Y.2d 473, 191 N.E.2d 279, 240 N.Y.S.2d 743 (1963).

${ }^{32} 65$ N.Y.2d 189, 480 N.E.2d 679, 491 N.Y.S.2d 90 (1985).

33 JUENGER, Friedrich K., op. cit., p. 147.
} 
"revolucionários", nem entre multilaterais e unilaterais, mas sim entre abordagens espaciais e valorativas (spatially oriented e value oriented approaches). ${ }^{34}$

As abordagens valorativas seriam eminentemente teleológicas, aquelas que se preocupam clara e primordialmente com o resultado material que será obtido para o caso de acordo com a lei substantiva que o regerá. Seguindo esta linha de pensamento, Juenger chega a advogar a superação do método conflitual para a solução de situações pluriconectadas pelo método uniformizador do DIP. Neste sentido, a abordagem teleológica seria muito mais adequadamente implementada se a comunidade internacional (neste caso, através da contribuição preponderante e construtiva dos diversos tribunais nacionais) chegasse a um consenso acerca das normas materiais a serem aplicadas em casos transnacionais. Este teria sido, aliás, o método desenvolvido pelos romanos em seu ius gentium, e pelos mercadores medievais através da lex mercatoria - um conjunto de princípios e regras substantivas que regem o comércio internacional até os dias de hoje. ${ }^{35}$

No entanto, considerando-se ainda a dificuldade de se estabelecer um corpo de normas gerais aplicáveis a situações pluriconectadas pelos diversos tribunais locais, não se abandona, mesmo para esta posição doutrinária, o papel construtivo das regras de conexão - se não para ajudar a construir este direito uniformizado, ao menos para garantir a orientação teleológica do método conflitual pelo juiz do foro, para aqueles que acreditam ser impossível a uniformização universal e geral de regras materiais aplicáveis a casos transnacionais. Tais regras de conexão devem orientar o juiz a perseguir determinados valores substantivos, conhecidos, portanto, também pelas partes, o que não deixaria de contribuir para as tão desejadas estabilidade, segurança e previsibilidade das decisões. Juenger sugere como exemplo a seguinte regra acerca da lei aplicável à responsabilidade civil por fato do produto:

"In selecting the rules of decision applicable to any issue a multistate products liability case presents the court will take into account the laws of the following jurisdictions:

(a) the place where the injury occurred,

\footnotetext{
${ }^{34}$ Ibidem, p. 154.
} 
(b) the place where the conduct causing the injury occurred, and

(c) the home state (habitual residence, place of incorporation or principal place of business) of the parties.

"As to each issue, the court shall select from the laws of these jurisdictions the rule of decision that most closely accords with modern products liability standards". 36

Uma regra como esta permitiria que o juiz justificasse sua decisão por meio de uma tendência internacional de se escolher a lei mais favorável aos consumidores e a terceiros vitimados no ilícito.

\section{Perspectivas para o DIP Brasileiro}

As regras de DIP brasileiras vêm previstas, basicamente, na Lei de Introdução ao Código Civil brasileiro (LICC) - Decreto-lei n. 4.657, de 4 de setembro de 1942. A lei é antiga, e conserva ainda regras de conexão rígidas e mecânicas. Assim é que, por exemplo, o seu artigo $8^{\circ}$ determina que "para qualificar os bens e regular as relações a eles concernentes, aplicar-se-á a lei do país em que estiverem situados" (lex rei sitae), o artigo $9^{\circ}$ preceitua que "para qualificar e reger as obrigações, aplicar-se-á a lei do país em que se constituírem" (lex loci actus, lex loci contractus e lex loci delicti) e o artigo 10 que "a sucessão por morte ou por ausência obedece à lei do país em que era domiciliado o defunto ou o desaparecido, qualquer que seja a natureza e a situação dos bens".

Entrou em vigor no início de 2003 o novo Código Civil brasileiro (Lei n. 10.406, de 10 de janeiro de 2002), mas se perdeu, contudo, mais uma oportunidade de se reformar também a LICC. Com efeito, não é de hoje que surgem propostas de modernização do DIP brasileiro. Na década de 1960, por exemplo, Haroldo Valladão redigiu um Anteprojeto de Lei Geral de Aplicação das Normas Jurídicas - um extenso diploma de sobredireito que modificava vários aspectos da LICC de 1942, entre eles, o "princípio da proteção à parte mais fraca e normas unilaterais de proteção aos brasileiros" - que por duas vezes não chegou à aprovação no Congresso (1970 e

\footnotetext{
${ }^{35}$ Ibidem, p. 165-169.
} 
1984). ${ }^{37}$ Em 1994, formou-se uma comissão para elaborar um projeto de lei que substituísse a LICC. Surgiu então o Projeto de Lei n. 4.905/95 que, entre outras disposições, adotou o princípio da proximidade para a lei aplicável às obrigações contratuais, ao direito de família e a atos ilícitos. ${ }^{38} \mathrm{O}$ projeto não foi levado adiante, tendo sido retirado em $1996 .^{39}$

Está em tramitação no Senado Federal o Projeto de Lei de iniciativa do Senado n. 243 de 2002, que nada mais faz que compilar em um só diploma as disposições já existentes no Brasil tanto de DIP - aí incluído o direito processual internacional quanto de direito internacional público. O projeto simplesmente reproduz normas com suas deficiências atuais, se não as aumenta ainda mais.

Pelo que se pode observar, não é muito animadora a perspectiva de avanços no DIP brasileiro, ao menos no âmbito da legislação de fonte interna. Segundo Dolinger e Tiburcio, além de não se ter tomada qualquer iniciativa no sentido de substituir as regras de conexão fixas por princípios como o da lei do país com vínculos mais estreitos, tampouco se procurou introduzir, em nossa legislação, “o princípio generalizado da proteção em vários campos do direto como o favor negotii, o favor validatis, o favor testamentii e outras manifestações favoráveis à validação e operacionalização de relações jurídicas transnacionais de todas as espécies". ${ }^{40}$

Registre-se, entretanto, uma única regra material de DIP brasileira que se preocupa com o resultado. Trata-se do parágrafo $1^{\circ}$ do artigo 10 da LICC, que procura proteger o nacional brasileiro em caso de sucessão internacional. ${ }^{41}$ A norma prevista neste dispositivo ganhou status constitucional, na medida em que o artigo $5^{\circ}$, XXXI da Constituição brasileira determina que "a sucessão de bens de estrangeiros situados no País será regulada pela lei brasileira em benefício do cônjuge ou dos filhos brasileiros, sempre que não lhes seja mais favorável a lei do de cujos".

\footnotetext{
${ }^{36}$ Ibidem, p. 196-197.

${ }^{37}$ DOLINGER, Jacob, TIBURCIO, Carmen, op. cit., p. 81-82.

${ }^{38}$ Ibidem, p. 87-91.

${ }^{39}$ Ibidem, p. 87; RODAS, João Grandino. Falta a Lei de Introdução ao Código Civil. Gazeta Mercantil, 21 set. 2001 , p. A3.

${ }^{40}$ DOLINGER, Jacob, TIBURCIO, Carmen, op. cit., p. 94.

${ }^{41}$ ARAUJO, Nadia de, op. cit., p. 91.
} 
Afora este único caso, pode-se esperar algo de mais inovador - no que tange à possibilidade de tornar as regras de conexão menos indiferentes a valores substantivos - a partir de normas de DIP de fonte internacional, em especial das convenções da CIDIP $^{42}$ e do Mercosul, e do trabalho criativo da jurisprudência.

Quanto às convenções, destaca-se a Convenção Interamericana sobre o Direito Aplicável às Obrigações Contratuais (México, 1994), que consagra o princípio da proximidade para a determinação da lei aplicável aos contratos internacionais. Tendo sido assinada, mas ainda não ratificada pelo Estado brasileiro, esta convenção inova também ao incorporar a lex mercatoria, definindo-a como "os princípios gerais de direito comercial internacional aceito por organismos internacionais". 43

Quanto ao papel da jurisprudência, Nadia de Araujo sugere que os tribunais brasileiros apliquem normas previstas em disposições de convenções internacionais, ainda que estas não tenham sido ratificadas pelo Brasil, "substituindo as regras da LICC já ultrapassadas". ${ }^{44}$ Esta é, sem dúvida uma solução interessante, na medida em que tais normas podem ser invocadas a título de princípios gerais de direito. ${ }^{45}$

Nesse contexto surge a importância de um bom trabalho de argumentação jurídica por parte dos tribunais. De fato, esclarece que "quando o intérprete se depara com um problema plurilocalizado, haverá necessidade - considerando os vazios e pontos indeterminados - da realização de um trabalho criativo de interpretação, informado mais pelos princípios do que por regras de conexão, que podem não estar comprometidas com a solução mais justa do caso concreto" (grifo nosso). ${ }^{46}$

Ressalta-se, nesse sentido, a importância de autores como Chaïm Perelman, especialmente por sua obra Lógica jurídica - nova retórica, que mostra "como o juiz usa o seu poder discricionário para conciliar o respeito ao Direito e a procura de uma

\footnotetext{
${ }^{42}$ A Conferência Especializada Interamericana sobre DIP (CIDIP) reúne-se periodicamente, sob o patrocínio da Organização dos Estados Americanos, para produzir e aprovar convenções sobre DIP que são levadas à assinatura e à ratificação por seus Estados partes. DOLINGER, Jacob, op. cit., p. 75-76.

${ }^{43}$ ARAUJO, Nadia de, op. cit., p. 83.

${ }^{44}$ Ibidem, p, 92.

${ }^{45}$ Note-se que Valladão alegou a subsistência de um princípio jurídico da autonomia da vontade, de titularidade das partes contratantes, para a escolha da lei aplicável a contratos internacionais, mesmo não o tendo previsto expressamente a LICC. DOLINGER, Jacob, TIBURCIO, Carmen, op. cit., p. 88.

${ }^{46}$ ARAUJO, Nadia de, op. cit., p. 103.
} 
solução justa". ${ }^{47}$ Assim, em concepções jus-filosóficas como a do pós-positivismo, os princípios assumem importância vital na ponte entre direito e moral, servindo, ao lado das regras, como fundamento das pretensões normativas, da deliberação do juiz.

No caso do DIP brasileiro, a válvula de escape mais acessível ao julgador para fugir das normas de conexão rígidas tem sido o princípio da ordem pública e, nesse contexto, o parâmetro do princípio da dignidade da pessoa humana é de grande valia para balizar a sua aplicação. Assim sendo, "a ordem pública transforma-se em uma barreira à penetração de regras estrangeiras, ainda que indicadas pela regra de conexão, se em flagrante oposição aos valores fundamentais que o Direito interno quer garantir", 48

Confirma-se, assim, por outro lado, a crítica de Juenger de que a ordem pública, bem como outros princípios da "parte geral" de DIP estão demonstrando, de certo modo, o desprestígio da própria disciplina ao evidenciar as falhas do método conflitual e a verdadeira orientação finalística e material que está por trás da atuação cada vez mais intensa dos tribunais. Neste particular, seria mais apropriado que o DIP admitisse mais claramente a sua vocação teleológica de busca pela justiça substantiva. Contudo, sobretudo para ordenamentos como o brasileiro, resta um longo caminho a ser percorrido e, nesse campo, o recurso à argumentação jurídica tem um vasto potencial a ser explorado.

\section{Conclusões}

Ao final deste trabalho, concluímos que:

1. o recurso a um conjunto de normas específicas - o DIP - para a solução de conflitos pluriconectados é, mais que uma questão de cortesia dos foros nacionais, um imperativo de justiça que fundamenta a própria existência das regras de conexão em DIP;

\footnotetext{
${ }^{47}$ Ibidem, p. 105.

${ }^{48}$ Ibidem, p. 116. Sobre exemplos da utilização da ordem pública de STF brasileiro em casos de interesse para o DIP, ver ARAUJO, Nadia de, op. cit., p. 119-122.
} 
2. as regras de conexão clássicas (rígidas) têm sido contestadas - tanto pela doutrina como pelo que transparece na prática dos tribunais - eis que não apresentam compromisso com o resultado material a ser atingido pela aplicação do direito substantivo que indicam, e que a solução para evitar resultados injustos ou indesejáveis tem sido a manipulação de princípios da "parte geral" da disciplina, ou o desenvolvimento de métodos que permitam ao juiz levar em consideração outros elementos antes de determinar o direito aplicável;

3. o desenvolvimento de princípios mais flexíveis como o da proximidade e de princípios "unilaterais" de proteção à parte mais fraca diminuem os efeitos colaterais da aplicação das regras de conexão rígidas;

4. os ordenamentos nacionais devem progredir para a aceitação de princípios que levem em conta o caráter teleológico, finalístico, do DIP, a fim de que os julgadores tenham em mente, na determinação da lei aplicável, a promoção de valores substantivos, aí incluída a preocupação com a justiça material;

5. a argumentação jurídica e o recurso a princípios são ferramentas valiosas de que deve lançar mão o juiz em face de uma situação jurídica transnacional, mormente se se trata de um ornamento como o brasileiro, cujas normas de DIP encontram-se há muito defasadas.

\section{Referências}

ARAUJO, Nadia de. Direito internacional privado: teoria e prática brasileira. Rio de Janeiro: Renovar, 2003.

AUDIT, Bernard. Droit international privé. 3. ed. Paris: Economica, 2000.

BEVILÁQUA, Clovis. Direito internacional privado. 3. ed. Rio de Janeiro: Freitas Bastos, 1938. 
DOLINGER, Jacob. Direito internacional privado: parte geral. 5. ed. Rio de Janeiro: Renovar, 1997.

Evolution of principles for resolving conflicts in the field of contracts and torts. Recueil des Cours, Haia, t. 283, 2000.

DOLINGER, Jacob, TIBURCIO, Carmen. O DIP no Brasil no século XXI. Revista Mexicana de Derecho Internacional Privado. Número especial, 2000.

HOFFMANN, Bernd von. Internationales Privatrecht. 7. ed. Munique: Beck, 2002.

MIRANDA, Francisco Cavalcanti Pontes de. Tratado de direito internacional privado. Rio de Janeiro: José Olympio, 2 tomos, 1935.

JAYME, Erik. Identité culturelle et intégration: le droit international postmodern. Recueil des Cours. Haia, t. 251, 1995.

Le droit international privé du nouveau millénaire: la protection de la personne humaine face à la globalisation. Recueil des Cours, Haia, t. 282, 2000.

JUENGER, Friedrich K. Choice of law and multistate justice. Dordrecht: Martinus Nijhoff, 1992.

RODAS, João Grandino. Falta a Lei de Introdução ao Código Civil. Gazeta Mercantil, 21 set. 2001, p. A3.

VALLADÃO, Haroldo. Direito internacional privado. 4. ed. Rio de Janeiro: Freitas Bastos, v. 1, 1974. 